\title{
Ultrasonic investigation of the effect of S-PRG filler-containing coating material on bovine tooth demineralization
}

\author{
Ryosuke MURAYAMA, Tetsuya FURUICHI, Miho YOKOKAWA, Fuminori TAKAHASHI, Ryo KAWAMOTO, \\ Toshiki TAKAMIZAWA, Hiroyasu KUROKAWA and Masashi MIYAZAKI \\ Department of Operative Dentistry, Nihon University School of Dentistry, 1-8-13, Kanda-Surugadai, Chiyoda-ku, Tokyo 101-8310, Japan
Corresponding author, Masashi MIYAZAKI; E-mail: miyazaki-m@dent.nihon-u.ac.jp
}

\begin{abstract}
This study investigated the effect of a coating material containing S-PRG fillers on the demineralization of bovine enamel and dentin, by measuring changes in the transmitted ultrasonic velocity. Bovine enamel and dentin specimens with and without coating $(n=6$ for each condition) were cut into blocks, immersed in $0.1 \mathrm{M}$ lactic-acid buffer solution ( $\mathrm{pH}$ 4.75) for 10 min twice daily throughout the test period, and stored in a demineralising artificial saliva solution $(\mathrm{pH}$ 7.0) between treatments. The propagation time of longitudinal ultrasonic waves was measured by a pulser-receiver with a transducer. Data were evaluated using ANOVA followed by Tukey's HSD test $(\alpha=0.05)$. The sonic velocity decreased over time for specimens stored in demineralising solution; however, coated specimens had a significantly higher sonic velocity than those without coating. The coating material containing pre-reacted glass-ionomer fillers therefore appeared to reduce the demineralisation of enamel and dentin.
\end{abstract}

Keywords: Demineralisation, PRG filler, Ultrasonic velocity, Enamel, Dentin

\section{INTRODUCTION}

In the oral environment, tooth structures undergo continuous demineralization and remineralisation ${ }^{1}$. Tooth erosion is a chemical process in which the inorganic phase is demineralised, thereby reducing the hardness ${ }^{2)}$. Subsequent abrasive challenges by brushing can increase the loss of tooth tissue ${ }^{3}$. Hence, there is a need for protective methods to prevent tooth erosion.

A coating material containing surface reaction type pre-reacted glass-ionomer (S-PRG) fillers to control demineralization has recently been developed for professional applications. PRG fillers are produced by an acid-base reaction between fluoroaluminosilicate glass and polyacrylic acid in the presence of water, which preliminarily forms a stable phase within the glass particles ${ }^{4}$. A single-step adhesive containing PRG fillers was reported to release ions leading to the uptake of fluoride by adjacent enamel and dentin, which subsequently resulted in decreased demineralization in response to acidic attack ${ }^{5}$. The use of S-PRG fillers was shown to promote rapid fluoride release through ligand exchange within the pre-reacted hydrogel ${ }^{6}$. In addition to the $\mathrm{F}$ ion, the S-PRG fillers released $\mathrm{Al}, \mathrm{B}$, $\mathrm{Na}, \mathrm{Si}$ and $\mathrm{Sr}$ ions ${ }^{7}$. Silicate and fluoride strongly induce remineralization of the dentin matrix ${ }^{8}$. Strontium and fluoride also improve the acid resistance of teeth by converting hydroxyapatite to strontium apatite and fluoroapatite ${ }^{9}$. S-PRG fillers alter the $\mathrm{pH}$ of the surrounding environment within a weakly alkaline range when they come into contact with water or acidic solutions.

Non-invasive ultrasonic techniques have been used

Color figures can be viewed in the online issue, which is available at J-STAGE.

Received Jun 12, 2012: Accepted Jul 13, 2012

doi:10.4012/dmj.2012-153 JOI JST.JSTAGE/dmj/2012-153 in many fields, and the sonic properties of enamel and dentin have previously been investigated ${ }^{10)}$. Assuming that these tissues are two-component isotropic homogeneous mixtures of protein and apatite, differences in ultrasonic velocity could be related to differences in the degree of mineralization and histological structures, as the ultrasonic velocity increases proportionally with the volumetric concentration of the minerals ${ }^{11}$. The current study evaluated the effect of a coating material containing S-PRG fillers on the demineralization of bovine enamel and dentin, using ultrasonic techniques to determine the mineral loss. The null hypothesis was that the coating material containing S-PRG fillers could not prevent the demineralization of tooth substrates.

\section{MATERIALS AND METHODS}

\section{Fabrication of specimens}

In total, 42 freshly extracted bovine incisors, without cracks or erosion, were cleaned and stored in physiological saline for up to $2 \mathrm{wk}$. The teeth were longitudinally sliced (1 mm thickness) in the bucco-lingual direction with a low-speed diamond saw (Buehler Ltd., Lake Bluff, IL, USA). Each slab was carefully shaped into a rectangle $(4 \times 4 \times 1 \mathrm{~mm})$ using a super-fine diamond finishing point (ISO \#021; Shofu Inc., Kyoto, Japan). Dentin specimens were obtained from the labial surfaces of the bovine teeth to provide consistent orientation of the tubules with respect to the specimen surface. The specimen surfaces were ground successively on wet silicon-carbide paper with a grit size of $\# 600, \# 1200$, or $\# 2,000$. The thickness and size of the specimens were measured using a dial gauge micrometer (CPM15-25DM; Mitutoyo, Tokyo, Japan).

The six specimens in the demineralisation group 
were treated with undersaturated $0.1 \mathrm{M}$ lactic-acid buffer solution ( $\mathrm{pH} 4.75,0.75 \mathrm{mM} \mathrm{CaCl} \cdot 2 \mathrm{H}_{2} \mathrm{O}_{2}$ and 0.45 $\mathrm{mM} \mathrm{KH_{2 }} \mathrm{PO}_{4}$ ) for $10 \mathrm{~min}$, and then placed in artificial saliva $(\mathrm{pH} 7.0,14.4 \mathrm{mM} \mathrm{NaCl}, 16.1 \mathrm{mM} \mathrm{KCl}, 0.3 \mathrm{mM}$ $\mathrm{MgCl}_{2} \cdot 6 \mathrm{H}_{2} \mathrm{O}_{2}, 2.0 \mathrm{mM} \mathrm{K}_{2} \mathrm{HPO}_{4}, 1.0 \mathrm{mM} \mathrm{CaCl} \cdot 2 \mathrm{H}_{2} \mathrm{O}$ and $0.10 \mathrm{~g} / 100 \mathrm{~mL}$ sodium carboxymethyl cellulose [CMC$\mathrm{Na}$ ) twice daily throughout the 4-wk test period; between treatments, the specimens were stored in artificial saliva at $37^{\circ} \mathrm{C}$. The six specimens for each treatment time $(0$, 7, 14, 21 and $28 \mathrm{~d}$ ) in the PRG group had a thin film (approximately $10 \mu \mathrm{m}$ thickness) of coating material painted onto their surfaces and were light irradiated for $10 \mathrm{~s}$ prior to immersion in the demineralizing solution. Coating materials were removed from the tooth surfaces using a plastic spatula before measurement of ultrasonic wave propagation time. The six specimens in the control group were stored in the artificial saliva throughout the test period. Measurements were carried out daily for the first $7 \mathrm{~d}$, and subsequently at 14,21 , and $28 \mathrm{~d}$ after the start of the test period.

\section{Propagation time of ultrasonic waves}

The ultrasonic velocity was measured using a pulserreceiver (model 5900PR; Panametrics, Waltham, MA, USA), a transducer for longitudinal waves (V112; Panametrics) and an oscilloscope (Wave Runner LT584; LeCroy Corp., Chestnut Ridge, NY, USA) ${ }^{11)}$. Measurements were taken before, and 7, 14, 21 and $28 \mathrm{~d}$ after the start of the tests. The equipment was initially subjected to a standard calibration procedure with blocks made of type 304 stainless steel (2211M; Panametrics) at $2.5,5.0,7.5,10.0$ and $12.5 \mathrm{~mm}$ thickness.

The transducer was oriented perpendicular to the contact surface of each specimen, in order to obtain the echo signal. The ultrasonic waves propagated from the transducer to the tooth, were transmitted through the substrate, and were detected by a transmitter set on the opposite side. Each measurement was conducted at a mean \pm standard deviation (SD) temperature of $23 \pm 1^{\circ} \mathrm{C}$ and relative humidity $(\mathrm{RH})$ of $50 \pm 5 \%$ in a controlled room. Six specimens from each group were measured.

\section{Statistical analyses}

The sonic velocity data were analysed by two-way analysis of variance (ANOVA), with time and treatment as factors, and with time as a repeated measure. Posthoc pair-wise tests among groups were performed using Tukey's Honestly Significant Difference (HSD) test. The significance level was set at $\alpha=0.05$. Calculations were performed using Sigma Stat software Version 3.1 (SPSS Inc., Chicago, IL, USA).

\section{Laser Scanning Microscopy (LSM)}

Specimens from each condition were treated using the same methods and observed under a three-dimensional laser scanning microscope (VK-8700; Keyence Corp.,

Table 1 Average sonic velocities (m/s) of bovine enamel specimens according to treatments. Mean, with standard deviation in brackets $(n=6)$

\begin{tabular}{lccccc}
\hline \multirow{2}{*}{ Group } & \multicolumn{5}{c}{ Treatment time (days) } \\
\cline { 2 - 6 } & 0 & 7 & 14 & 21 & 28 \\
\hline Control & $5,091(89)^{\mathrm{a}, \mathrm{A}}$ & $5,083(86)^{\mathrm{a}, \mathrm{A}}$ & $5,080(88)^{\mathrm{a}, \mathrm{A}}$ & $5,081(89)^{\mathrm{a}, \mathrm{A}}$ & $5,077(92)^{\mathrm{a}, \mathrm{A}}$ \\
Demineralization & $5,022(43)^{\mathrm{a}, \mathrm{A}}$ & $4,894(48)^{\mathrm{a}, \mathrm{A}}$ & $4,803(58)^{\mathrm{a}, \mathrm{A}}$ & $4,795(60)^{\mathrm{b}, \mathrm{B}}$ & $4,774(77)^{\mathrm{b}, \mathrm{B}}$ \\
PRG & $5,003(59)^{\mathrm{a}, \mathrm{A}}$ & $5,178(59)^{\mathrm{a}, \mathrm{A}}$ & $5,207(62)^{\mathrm{a}, \mathrm{A}}$ & $5,198(62)^{\mathrm{a}, \mathrm{A}}$ & $5,219(64)^{\mathrm{a}, \mathrm{A}}$ \\
\hline
\end{tabular}

Within groups, means sharing the same lower-case superscript letter are not significantly different $(p>0.05)$.

Between groups at the same treatment times, means sharing the same upper-case superscript letter are not significantly different $(p>0.05)$.

Table 2 Average sonic velocities $(\mathrm{m} / \mathrm{s})$ of bovine dentin specimens according to treatments. Mean, with standard deviation in brackets $(n=6)$

\begin{tabular}{lccccc}
\hline \multirow{2}{*}{ Group } & \multicolumn{4}{c}{ Treatment time (days) } \\
\cline { 2 - 6 } & 0 & 7 & 14 & 21 & 28 \\
\hline Control & $3,783(75)^{\mathrm{a}, \mathrm{A}}$ & $3,776(75)^{\mathrm{a}, \mathrm{A}}$ & $3,740(64)^{\mathrm{a}, \mathrm{A}}$ & $3,776(77)^{\mathrm{a}, \mathrm{A}}$ & $3,778(76)^{\mathrm{a}, \mathrm{A}}$ \\
Demineralization & $3,675(52)^{\mathrm{a}, \mathrm{A}}$ & $3,551(53)^{\mathrm{a}, \mathrm{A}}$ & $3,532(53)^{\mathrm{a}, \mathrm{A}}$ & $3,516(54)^{\mathrm{b}, \mathrm{B}}$ & $3,497(54)^{\mathrm{a}, \mathrm{B}}$ \\
PRG & $3,565(57)^{\mathrm{a}, \mathrm{A}}$ & $3,593(85)^{\mathrm{a}, \mathrm{A}}$ & $3,600(86)^{\mathrm{a}, \mathrm{A}}$ & $3,600(85)^{\mathrm{a}, \mathrm{A}}$ & $3,627(51)^{\mathrm{a}, \mathrm{A}}$ \\
\hline
\end{tabular}

Within groups, means sharing the same lower-case superscript letter are not significantly different $(p>0.05)$.

Between groups at the same treatment times, means sharing the same upper-case superscript letter are not significantly different $(p>0.05)$. 
Osaka, Japan). Excitation light had a wavelength maximum at $658 \mathrm{~nm}$. The intensity of the excitation light as well as the amplification of the photomultiplier was kept constant during the investigation period. The size of the images recorded was $81.5 \times 71.5 \mu \mathrm{m}^{2}$, and the resolution was $1024 \times 768$ pixel. Images were recorded at four different locations on tooth surfaces.

\section{RESULTS}

The sonic velocities of bovine enamel and dentin under the different treatment conditions are shown in Tables 1, 2, Figs. 1, 2. The differences between the storage periods were greater than would be expected by chance after allowing for the effects of differences in treatment methods $(p<0.001)$ for both enamel and dentin specimens, so multiple comparisons were conducted on the data.

The average sonic velocity of intact bovine enamel in the control group ranged from 5,060 to $5,073 \mathrm{~m} / \mathrm{s}$, and did not vary significantly with treatment period. The sonic velocity in the demineralization group decreased over time, and was significantly lower than that in the control group at 21 and $28 \mathrm{~d}$. By contrast, the sonic velocity in the PRG group did not vary significantly with treatment period, and did not significantly differ from that in the control group during the test period.

The average sonic velocity of intact bovine dentin in the control group ranged from 3,720 to $3,726 \mathrm{~m} / \mathrm{s}$, and did not vary significantly with treatment period. Although there was no interaction between treatment time and treatment method $(p=0.201)$, similar trends in sonic velocity were seen in the demineralization and PRG groups for dentin specimens.

Representative LSMimages of the enamel and dentin specimens (Figs. 3, 4) illustrated the morphological differences between the treatments. Pronounced morphological changes to the tooth surfaces occurred in the demineralization group for both enamel and dentin specimens, and acidic attack increased the opening of the dentinal tubules. By contrast, the specimens in the

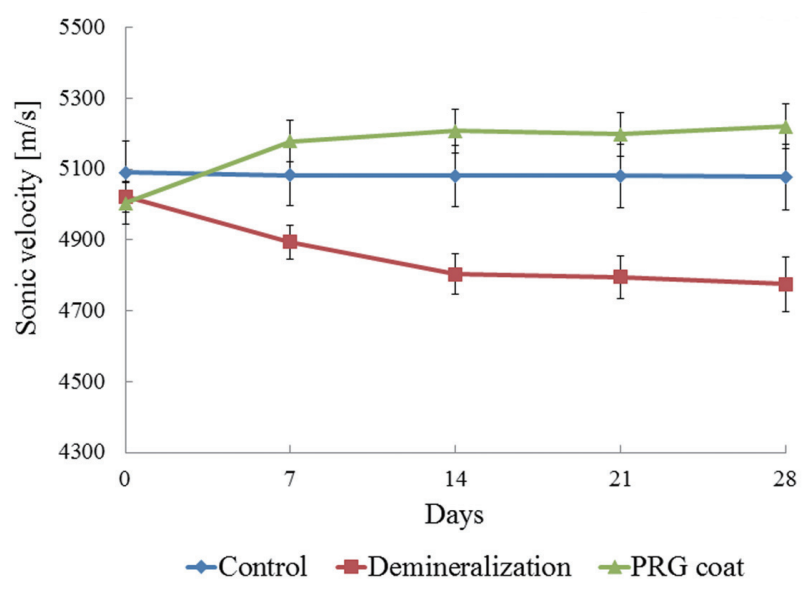

Fig. 1 The sonic velocities of bovine enamel under the different treatment conditions.
PRG group showed relatively minor or no morphological changes, and the dentinal tubules were obliterated after 28-d of treatment.

\section{DISCUSSION}

Although there is a consensus view that the use of human teeth is most relevant for in vitro studies, bovine teeth were chosen for the current study after considering the characteristics of the subject panel, the physical design of the model, the type of hard-tissue substrate, the method of assessing mineral status and the study design. Each of these key experimental parameters was carefully evaluated in relation to the objectives of the research ${ }^{12)}$. Bovine teeth are comparatively easy to obtain in large quantities and good condition, and have less variable composition than human enamel ${ }^{13)}$. Bovine teeth have large flat surfaces and have not experienced prior caries challenges that might affect test results. The mineral distribution in the carious lesions of bovine teeth is reportedly similar to that in human teeth, and the structural changes are similar ${ }^{14)}$. However, care should be taken when drawing conclusions from these data, as many factors affect results obtained under laboratory conditions.

Demineralization and remineralization processes on enamel and dentin are difficult to detect at early stages by visual inspection alone. There are many diagnostic techniques for detecting the demineralisation that occurs as a result of dental caries ${ }^{15-17)}$. Sonic velocity has been reported to be related to the mineral content of the body of enamel lesions ${ }^{18)}$. When a tooth surface suffers demineralisation, the mineral volume concentration and the specific sonic velocity are expected to decrease. The sonic velocity proportionally increases with the volumetric concentration of mineral components, and is an index of the degree of mineralisation; larger sonic velocity values are considered to indicate a higher degree of mineralisation. In the current study, the sonic velocities of the enamel specimens were much higher

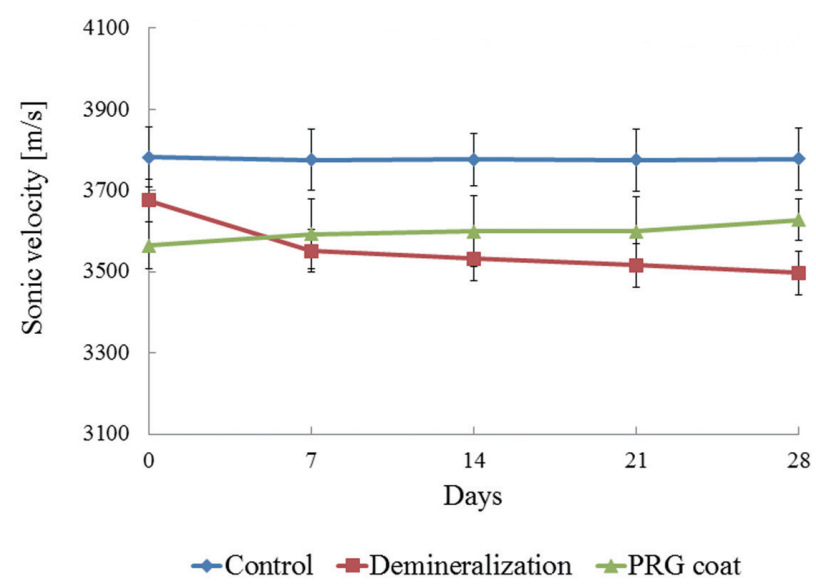

Fig. 2 The sonic velocities of bovine dentin under the different treatment conditions. 

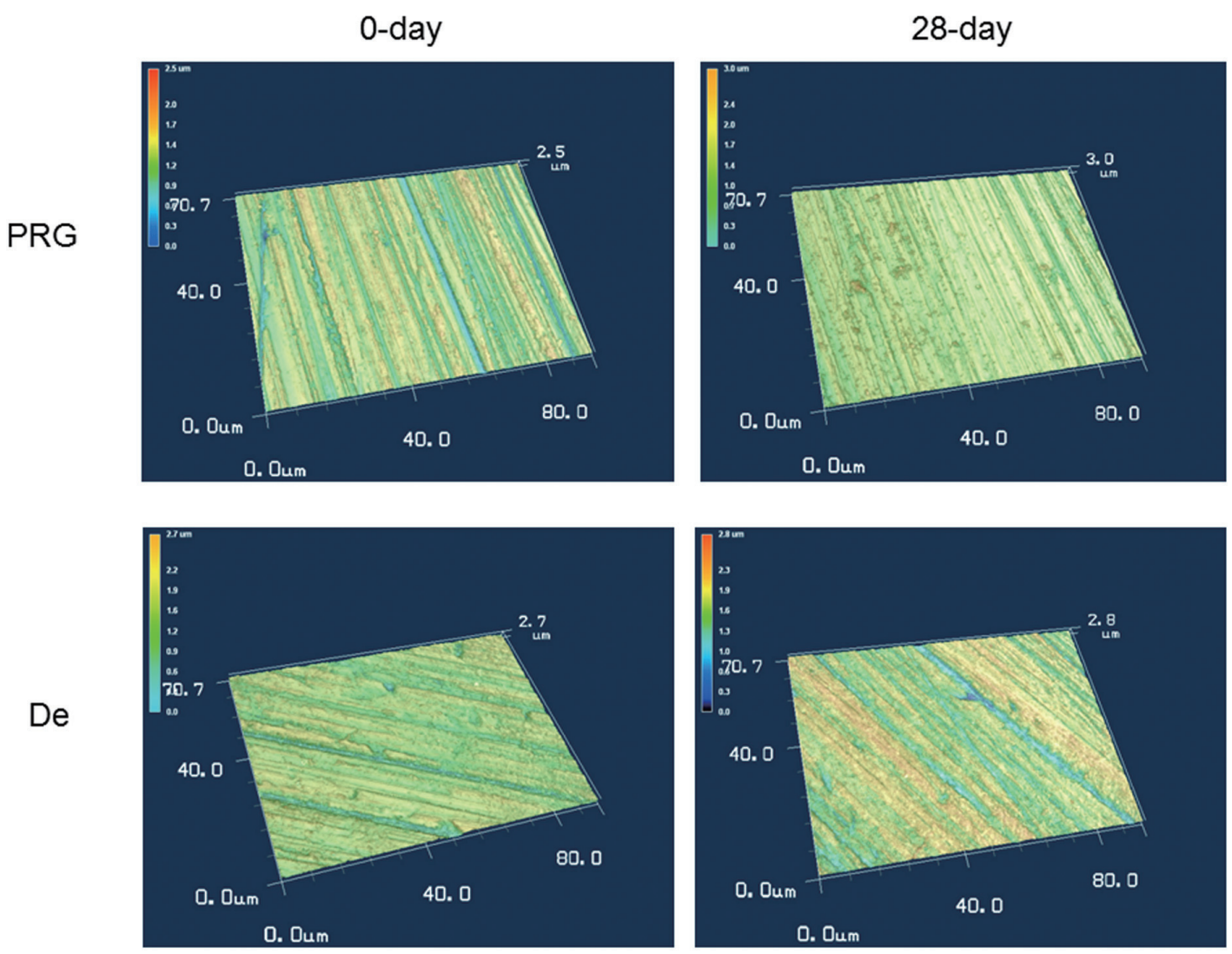

Fig. 3 Laser microscopic observations of enamel surfaces.

Pronounced morphological changes to the tooth surfaces occurred in the demineralisation group and acidic attack increased the roughness of the enamel surfaces. By contrast, the specimens in the PRG group showed relatively minor or no morphological changes.

than those of the dentin specimens, indicating higher hydroxyapatite content. As previously described, the orientation of the enamel prism and dentinal tubules might modify the sonic velocity ${ }^{19}$. According to the plane of section of the teeth, specimens are at different angles to the direction of the ultrasonic beam. To avoid this effect on the sonic velocity, enamel specimens were obtained from the labial surfaces of the bovine teeth in the current study.

Our results demonstrated changes in the ultrasonic velocity of the enamel and dentin specimens in the control group during demineralization, although they were not linear. The sonic velocities of the specimens in the PRG group did not change significantly with time. The application of a PRG coat resulted in the maintenance of normal sonic velocity for intact dentin, in contrast to the reduced velocity seen in the demineralisation group, suggesting that the PRG coating prevented tooth demineralisation. This conclusion was supported by the absence of signs of demineralisation in the PRG specimens according to LSM. On the dentin samples, the PRG coating produced a uniform and smooth surface with a greater loss of dentinal tubules compared with the demineralisation group. These characteristics might have been due to the presence of $\mathrm{Si}$ and $\mathrm{F}$ ions in the PRG coating, and consequent mineral deposition above the dentin surface.

S-PRG technology forms a stable glass-ionomer phase only on the surface of multi-functional glass particles, maintaining their basic properties and intended size. $\mathrm{Si}$ is thought to promote hydroxyapatite formation, as hydroxyapatite nucleation has been shown to be triggered by the presence of silica gel ${ }^{20}$. Hydrated silica gel has sufficient silanol groups to induce apatite nucleation on its own surface; nucleation then proceeds by the uptake of $\mathrm{Ca}$ and $\mathrm{P}$ from the surrounding environment. A previous report suggested that $\mathrm{Si}$ released from bioactive glass particles is absorbed onto the substance, thus providing sites for heterogeneous $\mathrm{CaP}$ nucleation. Once nucleated, it spontaneously forms a solution, resulting in a bonelike apatite layer ${ }^{21}$. Si was also reported to promote the mineralization of dentin by a mechanism based on the condensation of silicic acid to oligomers ${ }^{22}$. In addition, Si promote the mineralisation of dentin by a mechanism based on the condensation of silicic acid to oligomers. A sufficient quantity of $\mathrm{Si}$ is absorbed onto dentin with anionic groups $\left(\mathrm{SiO}^{-}\right)$within a short period of time, which then acts as a nucleation center for subsequent 

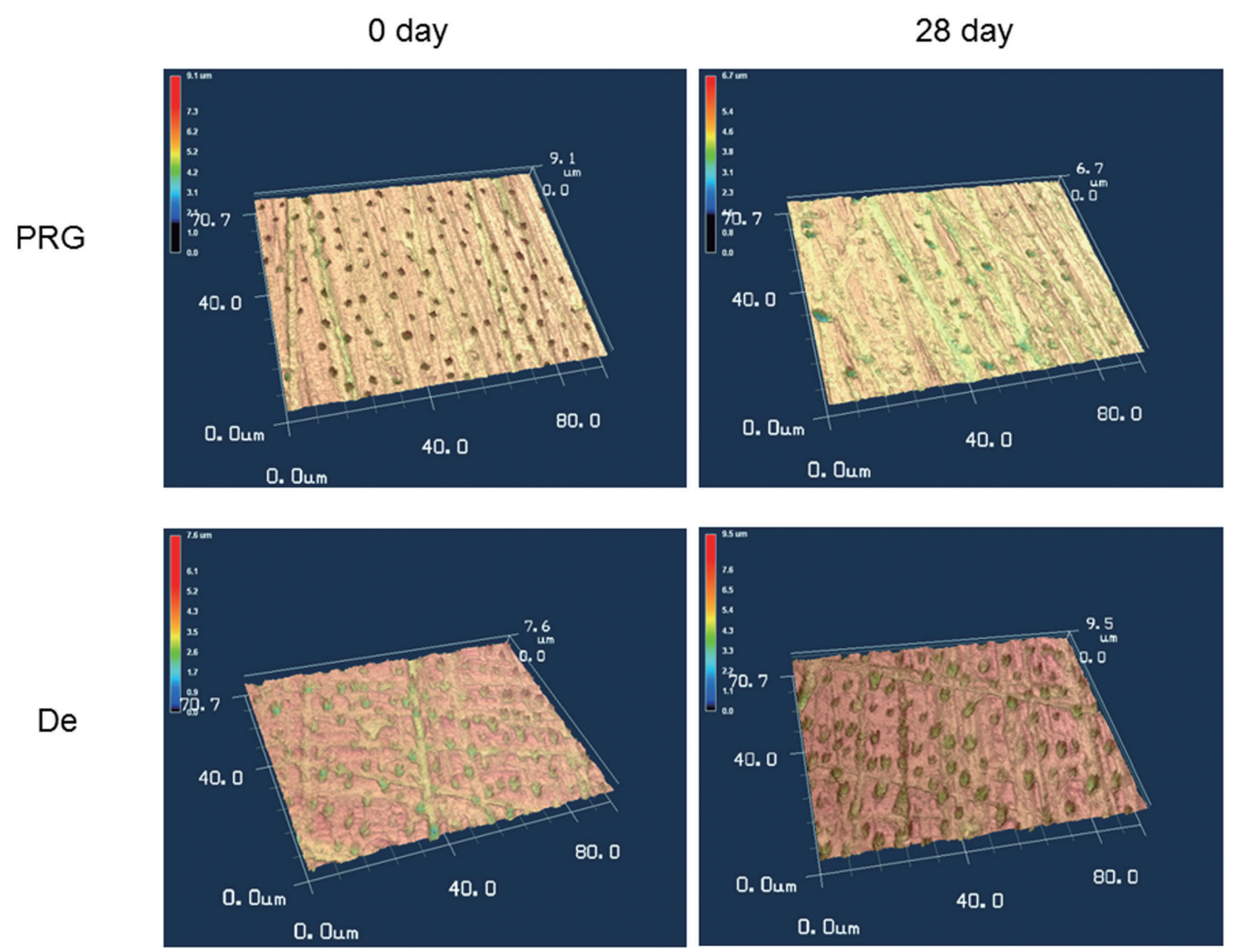

Fig. 4 Laser microscopic observations of dentin surfaces.

Pronounced morphological changes to the tooth surfaces occurred in the demineralisation group, and acidic attack increased the opening of the dentinal tubules. By contrast, the specimens in the PRG group showed relatively minor or no morphological changes, and the dentinal tubules were obliterated after 28 -d of treatment.

increased $\mathrm{CaP}$ formation ${ }^{23)}$. A sufficient quantity of $\mathrm{Si}$ is absorbed on dentin with anionic groups $\left(\mathrm{SiO}^{-}\right)$within a short period of time, which then acts as a nucleation center for subsequent, increased CaP formation. Another report suggested that Si released from bioactive glass particles absorbs on the substance, thus providing sites for heterogeneous CaP nucleation. Once nucleated this will spontaneously grow in a solution to form a bone-like apatite layer.

Sodium is leached from the surface of S-PRG fillers upon exposure to liquids, leaving behind a silica-rich surface that serves as a site for the re-deposition of calcium and phosphorus ions. A previous study reported that the calcium and hydroxyl groups of the hydroxyapatite in hard tooth tissues are substituted by $\mathrm{F}$ and $\mathrm{Sr}$ ions, forming strontium apatite and fluoroapatite, which increase the acid resistance of the structure ${ }^{24)}$. Sr and $\mathrm{Ca}$ are homologous elements, and the former is thought to promote calcification of the hard tooth tissue as a substitute for the latter. Sr reportedly has the capacity to enhance enamel remineralization in conjunction with $\mathrm{F}^{25)}$. Fluoride was shown to have the same effect on the improvement of the crystalline qualities of calcium phosphate ${ }^{26)}$. Sr and F released from the S-PRG filler might therefore improve the acid resistance of teeth by converting hydroxyapatite to strontium apatite and fluoroapatite, respectively.

Dental enamel largely comprises calcium-deficient carbonate hydroxyapatite (90-97 vol\%), whereas the value for dentine is considerably lower (around 65 vol\%). In environments supersaturated with hydroxyapatite, the amount of enamel and dentin remineralization is expected to differ, consistent with the present results. Dentin specimens with the PRG coating performed similarly to specimens in the control group. Although they were immersed in demineralisation solution twice daily during the experimental period, they did not show a decrease in ultrasonic velocity. The PRG coating therefore appeared to have a beneficial effect in preventing the demineralization of dentin. It has been reported that the remineralization of dentin with fluoride is more difficult to achieve than the remineralization of enamel ${ }^{27)}$. Although tooth substrate remineralization was enhanced in the presence of fluoride, it was observed only on the surface of etched enamel, and not on the surface of etched dentin under the same conditions ${ }^{28)}$. This could 
be attributable to the paucity of apatite seed crystallites available for heterogeneous crystal growth ${ }^{29}$.

In the present study, we showed that the coating material containing S-PRG fillers appeared to reduce the demineralization of enamel and dentin. The S-PRG filler has a modulation effect on the acidic conditions, enabling the $\mathrm{pH}$ of the surrounding environment to become weakly alkaline by coming into contact with water or acidic solutions. This acidic buffering was suggested to result in an immediate release of $\mathrm{Sr}, \mathrm{B}, \mathrm{Na}$ and $\mathrm{F}$ ions ${ }^{7}$. However, the current experimental study did not take into account all appropriate oral factors. Further researches are therefore needed to confirm our findings in a clinical setting.

\section{ACKNOWLEDGMENT}

This work was supported, in part, by a Grant-in-Aid for Scientific Research (C) $(23592810,24592883)$ from the Japan Society for the Promotion of Science. This project was also supported, in part, by the Sato Fund and by a grant from the Dental Research Center of Nihon University School of Dentistry, Japan.

\section{REFERENCES}

1) Featherstone JDB. The science and practice of caries prevention. J Am Dent Assoc 2000; 131: 887-899.

2) Lussi A, Kohler N, Zero D, Sshaffner M, Megert B. A comparison of the erosive potential of different beverages in primary and permanent teeth using an in vitro model. Eur J Oral Sci 2000; 108: 110-114.

3) Osborne-Smith KL, Burke FJT, Wilson NHF. The aetiology of the non-carious cervical lesion. Int Dent J 1999; 49: 139-143.

4) Ikemura K, Tay FR, Endo T, Pashley DH. A review of chemicalapproach and ultramorphological studies on the development of fluoride-releasing dental adhesives comprising new prereacted glass ionomer (PRG) fillers. Dent Mater J 2008; 27: 315-339.

5) Ikeumura K, Tay FR, Kouro Y, Endo T, Yoshiyama M, Miyai $\mathrm{K}$, Pashley DH. Optimizing filler content in an adhesive system containing pre-reacted glass-ionomer fillers. Dent Mater 2003; 19: 137-146.

6) Han L, Okamoto A, Fukushima M, Okiji T. Evaluation of a new fluoride-releasing one-step adhesive. Dent Mater J 2006; 25: 509-515.

7) Fujimoto Y, Iwasa M, Murayama R, Miyazaki M, Nagafuji A, Nakatsuka T. Detection of ions released from S-PRG fillers and their modulation effect. Dent Mater J 2010; 29: 392-397.

8) Saito T, Toyooka H, Ito S, Crenshaw MA. In vitro study of remineralization of dentin: effects of ions on mineral induction by decalcified dentin matrix. Caries Res 2003; 37: 445-449.

9) Thuy TT, Nakagaki H, Kato K, Hung PA, Inukai J, Tsuboi S, Nakagaki H, Hirose MN, Igarashi S, Robinson C. Effect of strontium in combination with fluoride on enamel remineralization in vitro. Arch Oral Biol 2008; 53: 10171022.

10) Yamaguchi K, Miyazaki M, Takamizawa T, Inage H, Moore BK: Effect of CPP-ACP paste on mechanical properties of bovine enamel as determined by an ultrasonic device. J Dent 2006; 34: 230-236

11) Takubo C, Yasuda G, Murayama R, Ogura Y, Tonegawa M, Kurokawa H, Miyazaki M. Influence of power density and primer application on polymerization of dual-cured resin cements monitored by ultrasonic measurement. Eur J Oral Sci 2010; 118: 417-422.

12) Yassen GH, Platt JA, Hara AT. Bovine teeth as substitute for human teeth in dental research: a review of literature. J Oral Sci 2011; 53: 273-582.

13) Edmunds DH, Whittaker DK, Green RM. Suitability of human, bovine, equine, and ovine tooth enamel for studies of artificial bacterial carious lesions. Caries Res 1988; 22: 327336.

14) Laurance-Young P, Bozec L, Gracia L, Rees G, Lippert F, Lynch RJ, Knowles JC. A review of the structure of human and bovine dental hard tissues and their physicochemical behaviourin relation to erosive challenge and remineralisation. J Dent 2011; 39: 266-272.

15) Anttonen V, Seppä L, Hausen H. Clinical study of the use of the laser fluorescence device DIAGNOdent for detection of occlusal caries in children. Caries Res 2003; 37: 17-23.

16) Higham SM, Pretty IA, Edgar WM, Smith PW. The use of in situ models and QLF for the study of coronal caries. J Dent 2005; 33: 235-241.

17) Pretty IA. Caries detection and diagnosis: novel technologies. J Dent 2006; 34: 727-739.

18) Ng SY, Ferguson MWJ, Payne PA, Slater P. Ultrasonic studies of unblemished and artificially demineralized enamel in extracted human teeth: a new method for detecting early caries. J Dent 1988; 16: 201-209.

19) Peck SD, Rowe JM, Briggs GA. Studies on sound and carious enamel with the quantitative acoustic microscope. J Dent Res 1989; 68: 107-112.

20) Li P, Ohtsuki C, Kokubo T, Nakanishi K, Soga N, Nakamura $\mathrm{T}$, Yamamuro T. Effects of ions in aqueous media on hydroxyapatite induction by silica gel and its relevance to bioactivity of bioactive glasses and glass-ceramics. J Appl Biomater 1993; 4: 221-229.

21) Tanahashi M, Yao T, Kokubo T, Minoda M, Miyamoto T, Nakamura T, Yamamoto T. Apatite coated on organic polymers by biomimetic process: improvement in its adhesion to substrate by $\mathrm{NaOH}$ treatment. J Appl Biomater 1994; 5: 339-347.

22) Miyaji F, Kim HM, Handa S, Kokubo T, Nakamura T. Bonelike apatite coating on organic polymers: novel nucleation process using sodium silicate solution. Biomaterials 1999; 20: 913919.

23) Forsback AP, Areva S, Salonen JI. Mineralization of dentin induced by treatment with bioactive glass $\mathrm{S} 53 \mathrm{P} 4$ in vitro. Acta Odontol Scand 2004; 62: 14-20.

24) Featherstone JD, Shields CP, Khademazad B, Oldershaw MD. Acid reactivity of carbonated apatites with strontium and fluoride substitutions. J Dent Res 1983; 62: 1049-1053.

25) Thuy TT, Nagasaki H, Kato K, Hung PA, Inukai J, Tsuboi S, Nagasaki H, Hirose MN, Igarashi S, Robinson C. Effect of strontium in combination with fluoride on enamel remineralization in vitro. Arch Oral Biol 2008; 53: 10171022.

26) ten Cate JM, Van Loveren C. Fluoride mechanisms. Dent Clin North Am 1999; 43: 713-742.

27) Damen JJ, Buijs MJ, ten Cate JM. Fluoride-dependent formation of mineralized layers in bovine dentin during demineralization in vitro. Caries Res 1998; 32: 435-440.

28) Aoba T. Solubility properties of human tooth mineral and pathogenesis of dental caries. Oral Dis 2004; 10: 249-257.

29) Qi YP, Li N, Niu LN, Primus CM, Ling JQ, Pashley DH, Tay FR. Remineralization of artificial dentinal caries lesions by biomimetically modified mineral trioxide aggregate. Acta Biomater 2012; 8: 836-842. 